\title{
COVID-19-related postponement of elective sexual or reproductive health operations deteriorates private and sexual life: an ongoing nightmare study
}

\author{
Nikolaos Pyrgidis ${ }^{1}$, loannis Sokolakis ID $^{1}$ and Georgios Hatzichristodoulou (D) ${ }^{1 凶}$ \\ (c) The Author(s), under exclusive licence to Springer Nature Limited 2022
}

We aimed to assess the impact of postponing sexual or reproductive health surgeries on patients' psychosocial distress and personal or occupational life during the COVID-19 pandemic. A total of 77 elective sexual or reproductive health surgeries were postponed. Of them, 38 patients are still on the waiting list for an appointment and, despite our efforts, we managed to operate only 39 patients when operation capacity returned to a normal level. At the time of surgery, all patients were requested to complete a 14-item questionnaire, assessing patients' perception of the COVID-19 pandemic. Patients marked the necessity of operation at the time of initial postponement as urgent and as highly urgent at the time of surgery. Due to the postponement of surgery, they reported experiencing severe restrictions in private life and more concerns and worries for their disease. Interestingly, patients who could not perform sexual intercourse due to the underlying disease wanted to receive surgery more urgently $(p=0.001)$ and displayed more restrictions in private life $(p=0.007)$. On the contrary, the duration of surgery postponement was not associated with worse outcomes. Overall, postponement of surgery poses a huge psychological burden that leads to further personal restrictions. Patients that cannot perform sexual intercourse should be prioritized for treatment.

IJIR: Your Sexual Medicine Journal (2022) 34:158-163; https://doi.org/10.1038/s41443-022-00538-8

\section{INTRODUCTION}

The COVID-19 pandemic altered the delivery of healthcare worldwide and led to a major disruption of routine hospital services [1]. Healthcare systems were temporarily restructured, and resources were reallocated to provide adequate capacity and support for the management of patients with COVID-19 predominantly during the crises of the pandemic $[2,3]$. During the first COVID-19 pandemic wave, elective surgeries were only rescheduled from April 2020 until June 2020 and healthcare systems could generally "compensate" this relatively short rescheduling [4]. On the contrary, during the second COVID-19 pandemic wave, elective surgeries had to be postponed for several months posing a huge psychological burden on patients, while backlogging and overloading the healthcare system $[5,6]$.

Shortly after the COVID-19 pandemic outbreak, the Guidelines Office of the European Association of Urology published recommendations on the management of urological conditions. All sexual or reproductive health operations such as penile prosthesis implantation, surgical correction of Peyronie's disease or congenital penile curvature, penile shaft reconstruction and circumcision or vasectomy under general anesthesia were classified as elective, low-priority surgeries with "no clinical harm" and had to be postponed [7, 8]. This postponement was mandatory to prioritize the management of oncological and emergency cases since sexual diseases were characterized as benign conditions or quality of life issues with no disease-related worse prognosis after rescheduling of their treatment $[9,10]$.
However, it should be highlighted that the reality is more complex and the consequences of postponing elective urological operations on patients' perception remain uncaptured [11]. Within this framework, we aimed to assess the impact of postponing sexual or reproductive health operations on patients' psychosocial distress, personal or occupational life and attitudes about the delivery of healthcare during the COVID-19 pandemic. Accordingly, we aimed to establish criteria on how to prioritize the rescheduling of these operations through a prospective cohort study.

\section{EVIDENCE ACQUISITION \\ Study design and selection criteria}

We performed a prospective, single-center, cohort study at the Urology Department of Martha-Maria Hospital, Academic Hospital of the Friedrich - Alexander University of Erlangen - Nuremberg, Nuremberg, Germany. We followed throughout the whole duration of the study the principles of the Helsinki Declaration, in lieu of a formal ethics committee approval, and we report our findings in accordance with the Strengthening the Reporting of Observational Studies in Epidemiology (STROBE) Statement for cohort studies [12]. All participants signed a written informed consent with guarantees of confidentiality before enrollment.

Due to the policy of our hospital, we were obliged to postpone all sexual or reproductive health operations under general anesthesia during the second COVID-19 pandemic wave in

1Department of Urology, 'Martha-Maria' Hospital Nuremberg, Nuremberg, Germany. ${ }^{\circledR}$ email: drhatzichristodoulou@gmail.com 
Germany (between October 2020 and June 2021). All operations under general anesthesia were, therefore, rescheduled between 1st July and 8th November 2021 and, consequently, all patients were recruited during this time span. However, even in the German healthcare system, which was generally well-prepared for the COVID-19 situation, the backlog and overload could not be avoided [13]. In particular, due to the new upcoming pandemic wave, we were obliged to postpone one again all elective sexual or reproductive health operations under general anesthesia at least until February 2022. On the contrary, surgical procedures under loco-regional anesthesia were further continued during the exacerbations of the COVID-19 pandemic, since they did not lead to an additional burden on the healthcare system.

The predefined inclusion criteria of this cohort study comprised: (i) males with any sexual or reproductive health disease (Peyronie's disease, erectile dysfunction, congenital penile curvature, phimosis, infertility or other conditions) requiring elective surgical correction under general anesthesia and; (ii) postponement of this elective surgical treatment due to the COVID-19 pandemic for at least three months between October 2020 and June 2021 (iii) sexually active males on a stable relationship. On the contrary, the predefined exclusion criteria comprised (i) postponement of surgical treatment for reasons not relevant to the COVID-19 pandemic and; (ii) patient age less than 18 years.

\section{Patient evaluation}

At initial screening, all male patients with a sexual or reproductive health disease proceeded to the outpatient clinic of our department after a negative COVID-19 PCR testing. By applying strict protective hygiene standards, a study author evaluated all eligible patients through detailed medical and sexual history, extensive physical examination, as well as through appropriate laboratory and ultrasonography tests. Moreover, all males were asked whether they could perform sexual intercourse due to the underlying sexual or reproductive health disease, using the relevant question of the International Index of Erectile Function. After establishing the diagnosis requiring surgical correction under general anesthesia, we informed all patients who were evaluated between October 2020 and June 2021 that we were obliged to postpone their operation due to their elective, non-lifethreatening condition, in line with the COVID-19 restrictions. All patients were also reassured that they would receive in time an appointment for surgery when the operation capacity would return to a normal level. In cases of emergency or further disease progression, we underlined to all patients that we could reevaluate them at any time.

\section{Questionnaire}

All patients with a postponed sexual or reproductive health operation were contacted from 1st July to 8th November 2021 for a new appointment. Given that no criteria on the matter exist, we predominantly prioritized patients on the waiting list based on the duration of their disease and the previous delay of their surgery. Those patients who ultimately proceeded for surgery were requested to complete a 14-item, 5-point Likert scale questionnaire which was developed for the purpose of the study. Considering that relevant questionnaires in urology are lacking, we based its development on published work from other surgical specialties, after consulting all co-authors [14]. All patients completed this questionnaire at the time of the operation. The applied questionnaire is presented in Data Supplement.

\section{Outcomes}

The primary outcome of the study was the impact of surgery postponement on patients' personal life. Secondary outcomes included: (i) the impact of surgery postponement on patients' perceptions about the treating physicians and the healthcare system and; (ii) the impact of surgery postponement on patients' occupational life. We also aimed to establish criteria on how to prioritize the rescheduling of sexual or reproductive health operations when operation capacities will again return to a normal level. In this scope, a subgroup analysis was undertaken to evaluate whether patients who cannot perform penetrative sexual intercourse due to the underlying preoperative disease reported worse outcomes. For the purpose of this analysis, patients were separated into two groups based on their ability to perform penetrative sexual intercourse. Similarly, a further subgroup analysis was performed to explore whether patients with a longer postponement of surgery displayed worse outcomes. For the purpose of this analysis, patients were separated into two groups (patients waiting for more than 6 months for surgery and patients waiting for less than 6 months for surgery).

\section{Statistical analysis}

We summarized the baseline characteristics of all participants with descriptive statistics. More specifically, continuous variables were presented as mean with standard deviation and categorical variables were summarized as frequencies with proportions. To perform the subgroup analyses, continuous variables were compared using the two-sample $t$ test or Mann-Whitney test based on normality. Normality was assessed statistically with the Shapiro-Wilk test and visually with histograms, P-P and Q-Q plots. All statistical analyses were undertaken in the $\mathrm{R}$ software (version 3.6.3) and, for all measures, two-sided $p$ values lower than 0.05 were considered statistically significant.

\section{RESULTS}

\section{Baseline evaluations}

A total of 160 male patients visited the outpatient clinic of our department due to a sexual or reproductive health disease requiring treatment between October 2020 and June 2021. In 77 cases, elective surgical correction under general anesthesia was mandatory but had to be postponed due to the restrictions of the second COVID-19 pandemic wave. Subsequently, we aimed to reschedule these operations when the restrictions applied by the German authorities were removed. Therefore, these patients were contacted for a surgical appointment from 1st July 2021. Due to the backlog and overload of the German healthcare system, 38 patients are still on the surgery waiting list of our department, with this number increasing since all elective surgeries were canceled again due to the new COVID-19 crisis. It should be stressed that we are daily facing the distress of these patients, who are contacting our department regularly to guarantee an appointment at the earliest possible date.

Despite our efforts, we managed to operate only 39 patients from 1st July 2021 until 8th November 2021 when the operation capacity returned shortly to a normal level. All operated patients completed the developed questionnaire. Patients were operated after a delay of $8 \pm 4.21$ months. Their mean patient age was 52.4 \pm 4.1 years and their mean body mass index was $22.1 \pm 1.1 \mathrm{~kg} / \mathrm{m}^{2}$. Among the operated patients, 24 (61.5\%) underwent surgical correction of Peyronie's disease, $6(15.4 \%)$ received an inflatable 3 -piece penile prosthesis implantation due to refractory erectile dysfunction, $3(7.7 \%)$ underwent surgical correction of congenital penile curvature, $1(2.6 \%)$ underwent penile shaft reconstruction due to a paraffinoma and $5(12.8 \%)$ received circumcision and/or vasectomy under general anesthesia due to patients' preference. No perioperative and postoperative complications were observed in all patients. The step-by-step study protocol is illustrated in Fig. 1.

\section{Patient perception about postponement of surgery}

At the preoperative evaluation, all patients completed the 14-item 5 -point Likert scale questionnaire. Based on this questionnaire, the patients who ultimately underwent surgery marked the necessity 


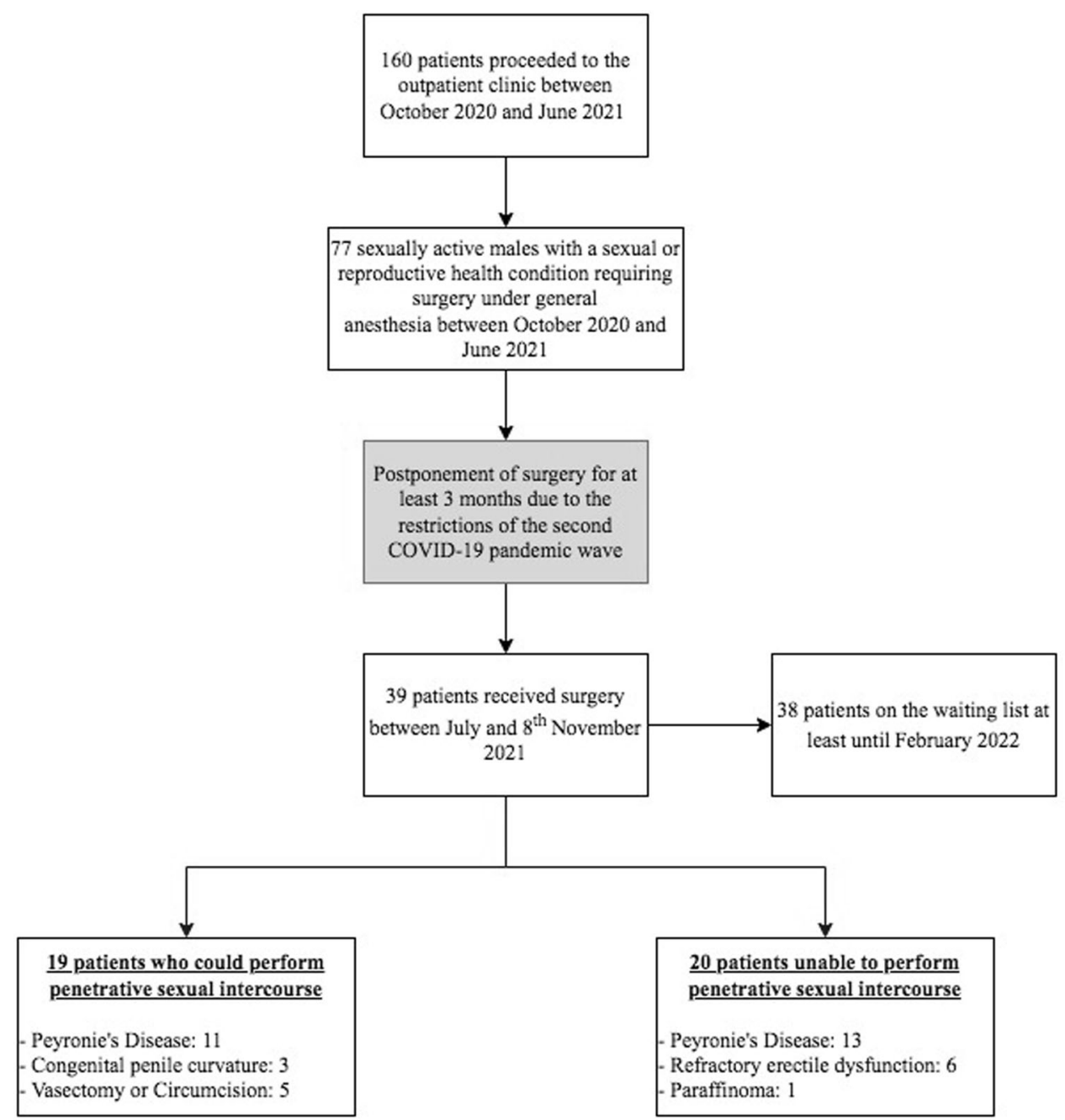

Fig. 1 Step-by-step study protocol. From 160 patients proceeding to our outpatient clinic during the study period, a total of 39 patients received surgery, while 38 are still on the waiting list.

of operation at the time of initial postponement as urgent $(4 \pm$ $0.87)$ and as highly urgent at the time of surgery $(4.6 \pm 0.71)$. They also highlighted that, due to the postponement of surgery, they underwent severe restrictions in private life $(4.1 \pm 1.17)$ and that they experienced more concerns for their disease (3.6 \pm 1.43$)$. On the contrary, these patients did not reconsider the necessity of surgery $(1.7 \pm 0.77)$ or did not want to postpone their surgery even further $(1.7 \pm 0.9)$. Given that sexual and reproductive health diseases do not cause pain when the indication for surgical correction is established, none of the participants experienced more pain or reported taking more painkillers due to the postponement of surgery. Of interest, despite all hardships, the included patients did not lose confidence in treating physicians and healthcare system. Additionally, they did not attempt to undergo surgery elsewhere $(1.7 \pm 0.77)$. The answers to all questions are available in Table 1.

\section{Effect of surgery postponement based on the ability to perform sexual intercourse}

Among patients receiving surgery, 19 (48.7\%) could perform penetrative intercourse. Of them, 11 were affected by Peyronie's disease, 3 by congenital penile curvature, whereas 5 wanted to undergo surgery due to phimosis and/or due to an imperative need for male sterilization. On the contrary, 20 (51.3\%) could not perform penetrative intercourse. Of them, 13 suffered from
Peyronie's disease, 6 from refractory erectile dysfunction and 1 from paraffinoma. Indeed, patients who could not perform sexual intercourse wanted to receive surgery more urgently $(p=0.001)$ and displayed more restrictions in private life $(p=0.007)$ compared to those who could still perform penetrative sexual intercourse due to the underlying disease. Moreover, these patients experienced more concerns $(p<0.001)$ and worries $(p=0.001)$ for their disease due to the postponement of surgery. The corresponding measures and comparisons can be seen in Table 2.

\section{Effect of duration of surgery postponement on patient- reported outcomes}

A total of $18(46.2 \%)$ patients were operated within six months after initial postponement. Conversely, 21 (53.8\%) patients underwent surgery after an initial postponement of at least six months. No statistically significant differences were observed between patients operated within six months and patients operated after six months in terms of the urgency of operation both at the time of initial postponement $(3.9 \pm 0.8$ vs. $4 \pm 0.95, p=$ $0.84)$ and at the time of surgery $(4.6 \pm 0.78$ vs. $4.7 \pm 0.66, p=0.64)$. Comparing the two groups, no significant differences were demonstrated regarding restrictions in private $(p=0.15)$ and occupational life $(p=0.6)$, as well as concerns $(p=0.15)$ and worries $(p=0.82)$ for their disease due to the postponement of 
surgery. Similarly, no significant differences were shown in all further patient-reported outcomes between the two groups. All relevant values and comparisons are depicted in Table 3.

\section{DISCUSSION}

Our findings indicate that postponement of surgery poses a huge psychological burden on patients requiring sexual or reproductive health operations. Irrespective of their disease, most patients reported that the urgency and necessity to be operated increased due to the initial cancellation of surgery. Accordingly, the included patients highlighted that they underwent severe restrictions in private life and that they experienced more concerns and worries for their disease due to this hardship. Still, these deteriorations do not seem to be further worsened by the duration of surgery postponement. On the contrary, patients who could not perform penetrative sexual intercourse reported worse outcomes compared to patients who, despite their underlying disease, could still perform penetrative sexual intercourse. Therefore, our study suggests that, when the operation capacity will return to a normal level, the prioritization of patients requiring sexual or reproductive health operations should mainly rely on their ability to perform sexual intercourse.

It should be noted that the postponement of surgery in patients with sexual or reproductive health conditions that cannot perform sexual intercourse may be considered an additional cause of male reproductive impairment. Even in the fifth decade of life, males suffering from severe erectile dysfunction, complex penile curvature or paraffinoma can father children after being operated $[15,16]$. Indeed, our study suggests that the impact of COVID-19 on the healthcare system may also indirectly affect male health and reproduction by postponing the correction of the underlying disease which impairs penetrative sexual intercourse and, in turn, fertility. Besides, COVID-19 disease per se negatively affects male health and reproduction by reducing testosterone levels and by damaging the male reproductive organ tract leading to decreased spermatogenesis and sexual dysfunction [17-19].

It should be highlighted that not only patients but also clinicians were negatively affected by the consequences of the COVID-19 pandemic. Similar to their treating patients, urologists were confronted by several physical and mental well-being problems [20, 21]. More specifically, they also faced personal and occupational restrictions and their attitude towards the delivery of healthcare was also reconsidered $[22,23]$. Of note, the cancelation of essential surgeries negatively impacted the operative experience and surgical training of residents in urology by reducing the number of everyday cases [24]. Accordingly, to reduce operative times and minimize perioperative complications, senior urologists were encouraged to perform the majority of the remaining cases [25]. Importantly, concerning academic activities, major congresses and courses were organized in a virtual or hybrid form, limiting the training possibilities of the urological community and hampering professional development $[26,27]$.

Even though multiple studies exploring the effect of COVID-19 on clinicians have been attempted in the literature, studies focusing on patients' well-being and patients' attitudes about the delivery of healthcare are scarce. To date, only studies in patients suffering from non-urological conditions have assessed the effect of COVID-19-related-cancelation of elective surgeries on patientreported outcomes [28]. In this scope, we provide, to our knowledge, the first study showcasing the devastating effect of postponement of elective urological surgeries on patients' perceptions. Importantly, our findings are in line with studies from other specialties suggesting that postponement of elective surgeries impairs quality of life and deteriorates patients' psychological health [29].

It should be noted that the present study should be interpreted with respect to some limitations relevant to the short study duration and the small number of participants requiring surgical 
Table 2. Comparison between male patients based on their ability to perform sexual intercourse.

\begin{tabular}{|c|c|c|c|}
\hline $\begin{array}{l}\text { Due to the postponement of my } \\
\text { surgery, I have... }\end{array}$ & $\begin{array}{l}\text { Ability to perform sexual } \\
\text { intercourse, } n=19 \text { (Mean } \pm \text { SD) }\end{array}$ & $\begin{array}{l}\text { Inability to perform sexual } \\
\text { intercourse, } n=20 \text { (Mean } \pm \text { SD) }\end{array}$ & $\begin{array}{l}\text { Between-group } \\
p \text { value }\end{array}$ \\
\hline $\begin{array}{l}\text { Attempted to undergo the surgery } \\
\text { elsewhere }\end{array}$ & $1.6 \pm 0.77$ & $1.8 \pm 0.77$ & 0.37 \\
\hline Worried more about my illness & $2.9 \pm 1.61$ & $4.5 \pm 0.76$ & 0.001 \\
\hline $\begin{array}{l}\text { Experienced restrictions in private } \\
\text { everyday life }\end{array}$ & $3.6 \pm 1.43$ & $4.6 \pm 0.5$ & 0.007 \\
\hline $\begin{array}{l}\text { Experienced restrictions in occupational } \\
\text { everyday life }\end{array}$ & $1.8 \pm 1.12$ & $1.9 \pm 1.04$ & 0.98 \\
\hline Lost faith in my treating hospital & $1.9 \pm 0.97$ & $1.7 \pm 0.86$ & 0.41 \\
\hline Lost faith in my treating surgeon & $1.7 \pm 0.89$ & $1.4 \pm 0.6$ & 0.34 \\
\hline
\end{tabular}

Values presented as mean scores with SD. The two-sample $t$ test or Mann-Whitney test was performed for comparisons between continuous variables based on normality. The bold cells indicate statistically significant $p$ values. Values presented as mean scores with SD.

$S D$ standard deviation.

Table 3. Comparison between male patients based on the duration of surgery postponement.

\begin{tabular}{|c|c|c|c|}
\hline $\begin{array}{l}\text { Due to the postponement of my } \\
\text { surgery, I have... }\end{array}$ & $\begin{array}{l}\text { Surgery postponement of }<6 \text { months } \\
n=18 \text { (Mean } \pm \text { SD) }\end{array}$ & $\begin{array}{l}\text { Surgery postponement of }>6 \text { months } \\
n=21 \text { (Mean } \pm \text { SD) }\end{array}$ & $\begin{array}{l}\text { Between-group } \\
p \text { value }\end{array}$ \\
\hline $\begin{array}{l}\text { Attempted to undergo the surgery } \\
\text { elsewhere }\end{array}$ & $1.7 \pm 0.83$ & $1.7 \pm 0.73$ & 0.83 \\
\hline Worried more about my illness & $3.8 \pm 1.56$ & $3.7 \pm 1.39$ & 0.82 \\
\hline $\begin{array}{l}\text { Experienced restrictions in private } \\
\text { everyday life }\end{array}$ & $4.4 \pm 0.85$ & $3.9 \pm 1.35$ & 0.15 \\
\hline $\begin{array}{l}\text { Experienced restrictions in } \\
\text { occupational everyday life }\end{array}$ & $1.9 \pm 1$ & $1.8 \pm 1.14$ & 0.6 \\
\hline Lost faith in my treating hospital & $2 \pm 0.97$ & $1.7 \pm 0.86$ & 0.27 \\
\hline Lost faith in my treating surgeon & $1.4 \pm 0.7$ & $1.7 \pm 0.8$ & 0.36 \\
\hline
\end{tabular}

Values presented as mean scores with SD. The two-sample $t$ test or Mann-Whitney test was performed for comparisons between continuous variables based on normality.

$S D$ standard deviation.

correction. Considering that we could not a priori predict how the COVID-19 pandemic would develop, we were unable to determine the necessary sample size for detecting statistical differences, when we designed the present study. Therefore, our findings might have been underpowered. Another important limitation of our study is that we used a non-validated questionnaire. Still, this questionnaire was based on relevant questionnaires from other specialties, as well as on expert opinion, and, thus, it may be validated in future studies. Of importance, although we dedicated an operating room once weekly for elective sexual or reproductive health operations, we managed to operate only 39 patients until the beginning of November 2021. Due to the new pandemic crisis with its mandatory restrictions in operation capacity, we were obliged once again to postpone all elective operations at least until February 2022. Given that patients will still develop sexual or reproductive health diseases requiring surgical correction, we 
estimate that when the healthcare system will return to a normal level, the backlog and overload will be inevitably even worse [30]. Based on the previous notion, we are planning a further in-depth analysis when this backlog is eased.

\section{CONCLUSION}

In light of the new pandemic crisis requiring further postponement of elective surgeries leading to a large backlog of patients with sexual or reproductive health diseases, we suggest prioritizing those who cannot perform sexual intercourse. Given that postponement of surgery has a devastating effect on most patients, efforts should be attempted to minimize this burden without endangering other patients. In such a prolonged emergency phase, non-oncological diseases should not be completely overshadowed, since they also affect personal wellbeing. Thus, plans must be put in place to help ease this backlog by continuing the delivery of safe, effective and patient-centered healthcare. We are, predominantly, the stewards of good healthcare practice and the greatest innovation would be to do what we already know. Therefore, we should respect the COVID-19 regulations and stay at the disposal of our patients by focusing on the consequences of postponing their treatment.

\section{REFERENCES}

1. Han E, Tan MMJ, Turk E, Sridhar D, Leung GM, Shibuya K, et al. Lessons learnt from easing COVID-19 restrictions: an analysis of countries and regions in Asia Pacific and Europe. Lancet Lond Engl. 2020;396:1525-34.

2. COVIDSurg Collaborative. Elective surgery cancellations due to the COVID-19 pandemic: global predictive modelling to inform surgical recovery plans. $\mathrm{Br} \mathrm{J}$ Surg. 2020;107:1440-9.

3. Rocco B, Sighinolfi MC, Sandri M, Altieri V, Amenta M, Annino F, et al. The dramatic COVID 19 outbreak in Italy is responsible of a huge drop of urological surgical activity: a multicenter observational study. BJU Int. 2021;127:56-63.

4. Tran LD, Rose L, Urech T, Dalton A, Wu S, Vashi AA. Short-term effects of canceled elective procedures due to COVID-19: evidence from the veterans affairs healthcare system. Ann Surg. 2021;274:45-9.

5. Dobbs TD, Gibson JAG, Fowler AJ, Abbott TE, Shahid T, Torabi F, et al. Surgical activity in England and Wales during the COVID-19 pandemic: a nationwide observational cohort study. Br J Anaesth. 2021;127:196-204.

6. Uimonen M, Kuitunen I, Seikkula H, Mattila VM, Ponkilainen V. Healthcare lockdown resulted in a treatment backlog in elective urological surgery during COVID-19. BJU Int. 2021;128:33-5.

7. Stensland KD, Morgan TM, Moinzadeh A, Lee CT, Briganti A, Catto JWF, et al. Considerations in the Triage of urologic surgeries during the COVID-19 pandemic. Eur Urol. 2020;77:663-6.

8. Ribal MJ, Cornford P, Briganti A, Knoll T, Gravas S, Babjuk M, et al. European Association of Urology Guidelines Office Rapid Reaction Group: an Organisationwide Collaborative Effort to Adapt the European Association of Urology Guidelines Recommendations to the Coronavirus Disease 2019 Era. Eur Urol. 2020;78:21-8.

9. Dotzauer R, Böhm K, Brandt MP, Sparwasser P, Haack M, Frees SK, et al. Global change of surgical and oncological clinical practice in urology during early COVID-19 pandemic. World J Urol. 2021;39:3139-45.

10. Phé V, Karsenty G, Robert G, Gamé X, Cornu J-N. Widespread postponement of functional urology cases during the COVID-19 pandemic: rationale, potential pitfalls, and future consequences. Eur Urol. 2020;78:4-5.

11. García-Rojo E, Manfredi C, Santos-Pérez-de-la-Blanca R, Tejido-Sánchez Á, GarcíaGómez B, Aliaga-Benítez M, et al. Impact of COVID-19 outbreak on urology surgical waiting lists and waiting lists prioritization strategies in the post-COVID-19 era. Actas Urol Esp Engl Ed. 2021;45:207-14.

12. von Elm E, Altman DG, Egger M, Pocock SJ, Gøtzsche PC, Vandenbroucke JP, et al. The strengthening the reporting of observational studies in epidemiology (STROBE) statement: guidelines for reporting observational studies. Lancet Lond Engl. 2007;370:1453-7.

13. Paffenholz $P$, Peine $A$, Fischer $N$, Hellmich $M$, Pfister $D$, Heidenreich $A$, et al. Impact of the COVID-19 pandemic on urologists in Germany. Eur Urol Focus 2020;6:1111-9.

14. Knebel C, Ertl M, Lenze U, Suren C, Dinkel A, Hirschmann MT, et al. COVID-19related cancellation of elective orthopaedic surgery caused increased pain and psychosocial distress levels. Knee Surg Sports Traumatol Arthrosc J ESSKA. 2021;29:2379-85.
15. Minhas S, Bettocchi C, Boeri L, Capogrosso P, Carvalho J, Cilesiz NC, et al. European Association of Urology Guidelines on Male Sexual and Reproductive Health: 2021 Update on Male Infertility. Eur Urol. 2021;80:603-20.

16. Salonia A, Bettocchi C, Boeri L, Capogrosso P, Carvalho J, Cilesiz NC, et al. European Association of Urology Guidelines on Sexual and Reproductive Health2021 Update: Male Sexual Dysfunction. Eur Urol. 2021;S0302-2838:01813-3.

17. Kadihasanoglu M, Aktas S, Yardimci E, Aral H, Kadioglu A. SARS-CoV-2 pneumonia affects male reproductive hormone levels: a prospective, cohort study. J Sex Med. 2021;18:256-64.

18. Lo SP, Hsieh T-C, Pastuszak AW, Hotaling JM, Patel DP. Effects of SARS CoV-2, COVID-19, and its vaccines on male sexual health and reproduction: where do we stand? Int J Impot Res. 2021. https://doi.org/10.1038/s41443-021-00483-y. Online ahead of print.

19. Cocci A, Giunti D, Tonioni C, Cacciamani G, Tellini R, Polloni G, et al. Love at the time of the Covid-19 pandemic: preliminary results of an online survey conducted during the quarantine in Italy. Int J Impot Res. 2020;32:556-7.

20. Abdessater M, Rouprêt $M$, Misrai V, Pinar U, Matillon X, Gondran-Tellier B, et al. COVID-19 outbreak situation and its psychological impact among surgeons in training in France. World J Urol. 2021;39:971-2.

21. Bakr AM, El-Sakka Al. Erectile dysfunction among patients and health care providers during COVID-19 pandemic: a systematic review. Int J Impot Res. 2022 https://doi.org/10.1038/s41443-021-00504-w. Online ahead of print.

22. Culha MG, Demir O, Sahin O, Altunrende F. Sexual attitudes of healthcare professionals during the COVID-19 outbreak. Int J Impot Res. 2021;33:102-9.

23. De Rose AF, Chierigo F, Ambrosini F, Mantica G, Borghesi M, Suardi $N$, et al. Sexuality during COVID lockdown: a cross-sectional Italian study among hospital workers and their relatives. Int J Impot Res. 2021;33:131-6.

24. Khusid JA, Kashani M, Fink LE, Weinstein CS, Gupta M. The impact of the COVID19 pandemic on urology residents: a narrative review. Curr Urol Rep. 2021;22:45.

25. Pang KH, Carrion DM, Rivas JG, Mantica G, Mattigk A, Pradere B, et al. The impact of COVID-19 on European Health Care and Urology Trainees. Eur Urol. 2020;78:6-8.

26. Woodruff $P$, Wallis CJD, Albers $P$, Klaassen Z. Virtual Conferences and the COVID19 Pandemic: are we missing out with an online only platform? Eur Urol. 2021;80:127-8

27. Nessaibia I, Sagese R, Atwood L, Bouslama Z, Cocci L, Merad T, et al. The way COVID-19 transforms our sexual lives. Int J Impot Res. 2021. https://doi.org/ 10.1038/s41443-021-00494-9. Online ahead of print.

28. Howard A, Hodgson $H$, Vun J, Panteli M, Palan J, Pandit H, et al. The patient's perspective on returning to elective surgery after COVID-19. Ann Surg. 2021;273: e41-3.

29. Sims BM, Patel AD, Garnica BG, Faraj MT, Tang A, Parsons T, et al. Effect of elective surgery cancellations during the COVID-19 pandemic on patients' activity, anxiety and pain. Br J Surg. 2021;108:e392-3.

30. López-Fando L, Bueno P, Carracedo D, Averbeck M, Castro-Díaz DM, ChartierKastler $\mathrm{E}$, et al. Management of female and functional urology patients during the COVID pandemic. Eur Urol Focus. 2020;6:1049-57.

\section{AUTHOR CONTRIBUTIONS}

All authors participated in the drafting, writing, and editing of the manuscript.

\section{COMPETING INTERESTS}

The authors declare no competing interests.

\section{ADDITIONAL INFORMATION}

Supplementary information The online version contains supplementary material available at https://doi.org/10.1038/s41443-022-00538-8.

Correspondence and requests for materials should be addressed to Georgios Hatzichristodoulou.

Reprints and permission information is available at http://www.nature.com/ reprints

Publisher's note Springer Nature remains neutral with regard to jurisdictional claims in published maps and institutional affiliations. 